\title{
THE GROWTH AND FRUITING OF GRACILARIA VERRUCOSA (HUDSON) PAPENFUSS
}

\author{
By W. EIFION JoNeS \\ Marine Biology Station, Menai Bridge, Anglesey
}

(Text figs. I-3)

Several workers have observed, in Europe and elsewhere, that Gracilaria verrucosa is a more conspicuous component of the flora in the summer months (Cotton, 1912, p. 134; Rosenvinge, 1931, pp. 602-6; Gibb, 1939, p. 378; Causey, Prytherch, McCaskill, Humm \& Wolf, 1946; May, 1948), with the natural inference that its growth rate is greater in that season. However, the quantity present on the shore at any time depends also on the rate of defoliation by the waves. This will be higher in winter. Observation under more controlled conditions was therefore considered desirable.

Fragmentary records of the fruiting of $G$. verrucosa extend over many years. Hudson ( 1762 , pp. 588, 59I) gave the fruiting period (for female gametophytes) as being from June to September. Greville (I830, p. I23) agreed but added that occasional fruiting plants could be found at all seasons. Feldmann ( 1954, p. 86) recorded, in Brittany, cystocarps in January, April, July, August, September, October and December and tetraspores in August and September. Rosenvinge (1931, pp. 602-6) recorded, in Denmark, ripe cystocarps in July and August; empty ones in October and April; ripe tetrasporangia in June, July and August and empty ones in October; spermatangia in July and August. The present attempt to obtain a more complete picture has involved the examination of collections of plants from various shores at all times of the year; and estimation of the relative numbers of cystocarpic and non-cystocarpic plants on a shore. These field observations have been supplemented by testing plants in the laboratory for their readiness to shed spores and the capacity of the latter to germinate.

\section{THE VEGETATIVE GROWTH CYCLE \\ Criterion of growth}

The increasing length of a frond of Gracilaria probably furnishes a satisfactory measure of its growth since, in a uniformly cylindrical thallus, the bulk is proportional to the length. However, the simple measurement of the maximum length of the thallus did not appear to be satisfactory, since the 
growth of the more or less numerous branches would not necessarily be represented by this. Instead, in the present investigation, the fresh weight of the plants concerned was periodically measured.

\section{Methods}

In their experiments on factors affecting growth in Gracilaria verrucosa in N. Carolina, Causey et al. (1946) measured the 'green weight' of the plants after shaking off the surface water. As the plants used in the present investigation were not large, incomplete removal of surface water was thought likely to cause inaccuracies, as was the inevitable loss of weight by desiccation during weighing; in addition the careful blotting of plants is very time-consuming. To avoid this, weighing was carried out with the plants completely immersed in sea water, as described elsewhere (Jones, 1959, p. I55).

The material used consisted of plants or parts of plants divided at the holdfast and attached by nylon fishing 'gut' to 'Tufnol' plastic bars. The bars were mounted in a box with sides, top and bottom of half-inch mesh wirenetting which allowed a free flow of water round the plants while preventing the entry of floating debris. The box was suspended in one compartment of an open-bottomed barge anchored in the Menai Straits. The bars, with the attached plants, were brought into the laboratory periodically for inspection.

Numerous algal spores settled on the plants while on the barge and a heavy growth of epiphytes resulted in which silt was often bound. This reduced the amount of light reaching the plant. In addition some shade was given by the sides of the barge and, occasionally, by masses of floating weed (Ascophyllum nodosum and Fucus vesiculosus) which entered the barge and had to be removed. These conditions did not appear to be ideal for the growth of the plants which, during the first season, did not survive indefinitely in an actively growing state. In the subsequent season a more continuous record was obtained. Epiphytes, which had to be removed laboriously by hand, were a major difficulty in the later stages of growth, particularly in the second season.

\section{Results}

In the first season batches of six plants were used which were replaced by freshly collected batches when signs of mortification appeared or when the growth of epiphytes became particularly heavy. Results were not obtained for all months: the general pattern was that a comparatively low growth rate of $\mathrm{I} \%$ increase in fresh weight per day was observed in November, December, January and April and that in May a sudden increase in the growth rate to $2.6 \%$ per day occurred. This rate was maintained through June and gradually declined through the summer, falling more rapidly with the approach of autumn.

These experiments also suggested that the growth rates of cystocarpic and tetrasporic plants were not always the same. In the second season, therefore, 
the growth rates of three cystocarpic and three tetrasporic plants were recorded separately. In this series the changes in weight of the same individuals were followed from September until the following July. Deterioration of the plants, resulting mainly from their having grown so large as to be damaged by abrasion against the sides of the box, then made it necessary to conclude the experiment. Fig. I shows the changes in the total weight of the three tetrasporic and three cystocarpic plants. In general these results confirm those of the previous season, showing a tendency for the weight of the plants to decline through the winter with a slight rise in early spring followed by a rapid increase in May. Examined separately, however, the results for tetrasporic and cystocarpic plants show some differences.

(i) The spring burst of growth began about a fortnight later in cystocarpic than in tetrasporic plants. A parallel increase in weight was shown by two additional batches, of three tetrasporic and three cystocarpic plants respectively, collected in late April and grown in the box together with the original plants during the period of the May increase. These results are included in Fig. I and offer some confirmation of the observations, the parallel being particularly close in the cystocarpic plants.

(ii) From September onwards, while the weight of the tetrasporic plants rose steadily, that of the cystocarpic decreased at almost the same rate. Occasional increases in the weight of the cystocarpic plants (as between I3 and 25 Oct. in Fig. I) suggest that their potential growth rate at that time of the year is as high as that of tetrasporic plants. Their loss of weight seems to result from more rapid decay of the thallus. It has been observed that decay in the autumn is more pronounced in cystocarpic plants, apparently because pathogens find easy entry into their thalli through the ostioles of cystocarps after spore shedding has ceased. Very frequently decay may be seen to be beginning in a cystocarp while the thallus remains healthy above and below it. Decay soon spreads to the thallus itself and that part above the diseased area breaks off and is lost. In tetrasporic plants decay is largely limited to damaged tips, spreading slowly down the branches and causing comparatively slow loss of material. Probably pathogenic organisms do not enter as easily into the comparatively small opening left after the discharge of the tetraspores, while the copious mucilage left in the cystocarp, and often exuded through the ostiole as fruiting finishes, offers a good substrate for the settlement and development of the spores of pathogens.

In the sheltered conditions of the raft a steady state was reached by the end of November in tetrasporic plants and by January in cystocarpic, during which loss and growth were roughly balanced and little change in weight occurred until the rapid spring growth commenced. 




Fig. I. A. Changes in the total weight of four groups of three plants of Gracilaria verrucosa grown on a barge in the Menai Straits. $\oplus$, tetrasporic, $\bigcirc$, cystocarpic, grown from September 1955; $\boxminus$, tetrasporic, $\square$, cystocarpic, grown from May 1956. The broken line in the period February-March shows the growth recorded without removing epiphytes which were removed at the beginning of April. The solid line gives the more correct picture of the growth of Gracilaria. B. Continuous line, sea surface temperatures (ro-day averages) over the same period, measured at Menai Bridge Pier. Dotted line, average illumination for Plymouth, 1930-37 (from Atkins, 1938, and Harvey, 1955).

\section{Discussion}

In these experiments the plants, though growing in the open, were not under exactly the same conditions as in a normal littoral habitat. In particular:

(i) There was no tidal effect, i.e. no emersion, no pressure fluctuation and no alteration of light intensity by absorption by varying depths of water. 
(ii) Although movement of the barge caused plants to sweep against the sides of the box, there was no effect comparable to wave action as on a beach.

(iii) Owing to shading by the sides of the barge the light intensity in the box was never as high as the maximum obtainable on the shore at the same season.

(iv) Temperature changes in the Straits are more pronounced than in the open sea. There may, for instance, be rather sudden falls of temperature in February to as little as $2^{\circ} \mathrm{C}$.

The effect of these differences, with the exception of the last, should be to even out the seasonal changes in weight so that, while the experiments indicate the general trend, more pronounced changes might be expected on the shore. This is particularly true of shelter from wave action; the loss resulting from wave damage is severe in winter on the shore and certainly greater than that shown in the experimental results. The equilibrium between the growth rate and the rate of loss by decay and damage, mentioned above, is not so readily established on the shore where plants decrease in size throughout the winter and early spring.

The results show an increase in the weight of both tetrasporic and cystocarpic plants in March. This may be attributed, in the main, to the growth of epiphytes which became noticeable at the end of February. Some real increase in weight did, in fact, occur during this period but was small, as shown by the values for 25 April when careful cleaning of the plants, with the removal of all epiphytes, was commenced. The spring burst of growth began about 3 weeks after this (in the tetrasporic plants) so that it seems that Gracilaria begins active growth later than some other species.

In considering the relationship of the seasonal environmental changes to the growth cycle the two factors with obvious summer maxima are the sea temperature and the daily quantity of light. Conversely, the acceleration of growth occurs when the supply of dissolved nitrogen and phosphorus in the sea water is approaching its lowest annual value (Harvey, 1955, pp. 44-59). In Fig. I the annual cycles of temperature and light are shown on the same time scale as the growth cycles of tetrasporic and cystocarpic plants over the period September 1955-July 1956. It will be seen that, whilst growth broadly follows the trend of both factors, there is no exact coincidence. For instance, the burst of growth in May does not coincide with a sudden increase in either temperature or light, which have both been increasing for several months before this. Certain correlations do, however, appear reasonable, though hypothetical at the moment.

Accepting the loss of weight of cystocarpic plants in autumn as being due to decay, the potential growth rate may best be seen in the tetrasporic plants. In these growth continued until late November, when, as has been noted above, it decreases below that required to maintain the weight of the plant. At this time the falling temperature of the sea reached about $8^{\circ} \mathrm{C}$. Until the end of April, when the growth rate again overtook the rate of loss, the tem- 
perature remained below $8^{\circ} \mathrm{C}$, suggesting that, under the conditions on the barge, this represents a critical temperature below which the level of metabolism of the plants is too low to replace all the material lost by accidental damage. The amounts of light available at these times are, on the other hand, very different. At the end of November the daily quantity of light is approaching its minimum value, while in late April it has reached about $85 \%$ of its maximum. This critical temperature hypothesis receives some support from the fact that a slight rise in the growth rate may be seen coincident with the rise in temperature after the February minimum; this is small and not necessarily significant but appears to occur in both tetrasporic and cystocarpic plants. Again, the results of Causey et al. (1946) are in general agreement with this hypothesis; from their observations on Gracilaria in N. Carolina they state that growth begins in spring when the water temperature rises above $10^{\circ} \mathrm{C}$ and ceases when it drops below $10^{\circ} \mathrm{C}$ in the autumn. It should be remembered, however, that although some growth occurred in the cystocarpic plants at the same time as the tetrasporic, the main burst of growth began a fortnight later, by which time the temperature had risen to nearly $10^{\circ} \mathrm{C}$.

This time lag may perhaps be explained by analogy with the behaviour of unicellular algae in culture. Spencer (I954) showed that when, after a period of growth in suboptimal conditions, the plants are subcultured to media containing ample nutrients, there is a time lag before rapid growth recommences. The duration of this lag is related to the length of the period of suboptimal nutrition. Something similar may be taking place in the present instance. Cystocarpic plants suffer greater loss by winter decay and damage than tetrasporic plants and may have larger deficiencies to make good in spring before rapid growth can begin.

When the necessary experimental facilities become available it is hoped that these questions will be more completely investigated.

\section{Ecological significance of the results}

The results described above are in agreement with the cycle of events observed on the shore, where plants reach their maximum size in late summer, suffer considerable defoliation in autumn and continue to be reduced by damage through the winter. The fact that growth continues to some extent through the winter, although it is usually outweighed by damage, is of significance in determining some of the variations in form of plants in exposed and sheltered habitats, which will be described in another paper.

\section{THE REPRODUCTIVE CYCLES}

\section{Tetraspores}

Tetraspore production begins early in the year. Plants may be found in February from the older parts of which almost all tetraspores have been shed 
but whose younger branches contain immature sporangia. Such plants have been found mainly in the more sheltered localities (such as Porth Penrhyn Mawr, within the Holyhead breakwater). Elsewhere there is little survival of the parts which bore tetraspores in the previous season and the tetrasporic plants found in February contain only immature sporangia. These are generally located in the distal parts of the branches, which are swollen to about twice the diameter of the sterile parts. This is a point of some taxonomic interest (Jones, 1957). No spores are shed naturally from plants brought into the laboratory at this stage. In March mature tetraspores can be found which, in the latter part of the month, are shed (though not as readily as later in the year) and begin division normally. Mature, viable tetraspores are produced continuously in the succeeding spring and summer months, the quantity increasing with the enlargement of the thalli. The maximum production appears to occur in July.

As autumn approaches an increasing number of plants is to be found which have shed most of their tetraspores. Such plants are common in August and, by October, the majority of the spores have been shed. As the loss by wave damage increases, less and less of the summer's tetrasporangial branches are to be found. However, as has been shown, vegetative growth continues into the autumn and early winter and, in the young branches resulting from this growth, some tetraspore production continues. Thus in November and December mature tetraspores may be found in the younger branches where their development causes a local swelling of the distal part of the branches similar to that seen in the early part of the year. Natural shedding and subsequent development of tetraspores has been observed in November from the young branches but the older parts of the thalli which produced spores in the summer do not readily shed any remaining spores after September. The tetraspores produced in the autumn branches form only a small proportion of the total crop. Fig. 2 summarizes the cycle of tetraspore production.

\section{Carpospores}

Female gametophytes bearing cystocarps may be found at all times of the year but the proportion of the total population which they constitute varies seasonally. Fig. 3 shows the percentage of plants bearing obvious cystocarps on the boulder beach at Dinas Dinlle. In recording these results the plants were not, as a rule, collected since the removal of samples of 100-150 plants on each visit would quickly destroy the population. Thus no differentiation of tetrasporic and male material was possible and, also, some underestimation of the total number of female plants might be expected in winter, when some plants bore only a few cystocarps which might be overlooked. This also occurred during the occasional rises in the sand level, particularly in the winter when, in general, the female gametophytes have suffered greater decay and damage and, being therefore smaller than the tetrasporophytes, are more 
likely to be obscured by the sand, as in the case of the first December value shown in Fig. 3. Nevertheless, the general trend is quite clear: plants bearing cystocarps are scarcest in April; their number increases in May and rises rapidly through the summer, reaching a maximum in autumn. The number

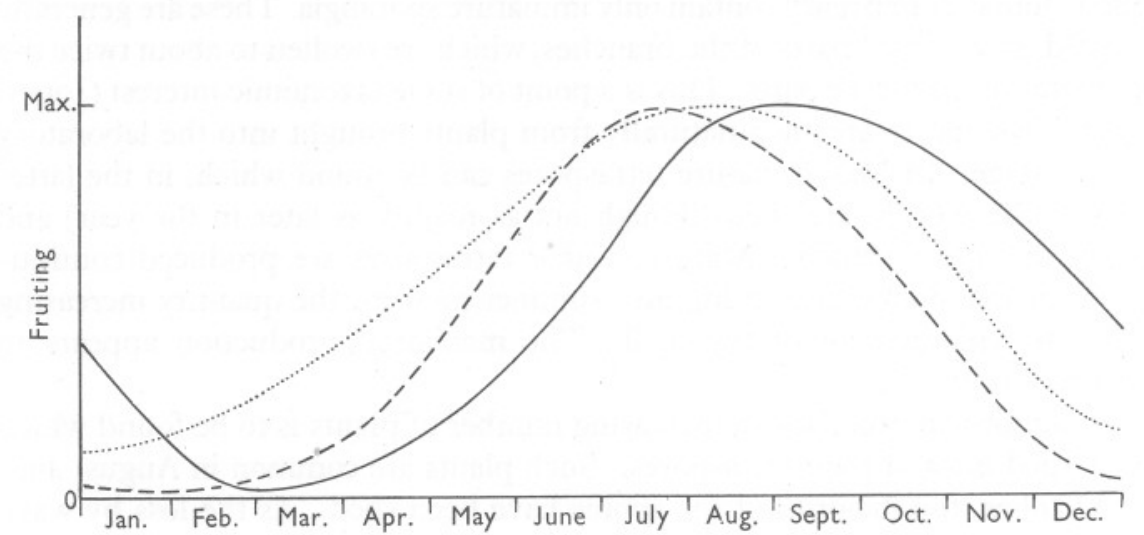

Fig. 2. Diagram of fruiting cycle in Gracilaria verrucosa indicating seasonal production of spores and spermatia. -, carpospores; -- -, tetraspores; ......., spermatia.

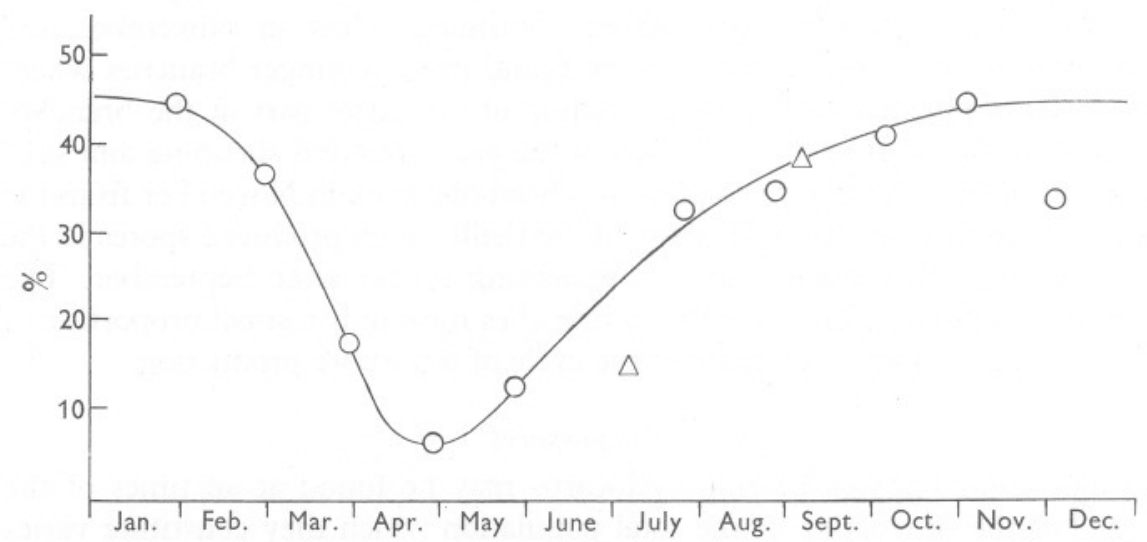

Fig. 3. Percentage of female gametophytes bearing cystocarps in a population of Gracilaria verrucosa at Dinas Dinlle. $\triangle$, I955; O, 1956.

remains high until January when a rapid fall begins and continues until the minimum is again reached. Except for a period in spring viable carpospores can be obtained at all times.

It should be pointed out that, although the maximum number of plants bearing cystocarps is found towards the end of November, this is not necessarily the time either of the largest total number of cystocarps or the maximum carpospore production. In fact the plants, in all but the most sheltered places, 
are considerably reduced in size by this time and the amount of frondage capable of bearing cystocarps is very much smaller than in July and August. Since the loss by decay and damage generally begins to be noticeable in late August and September, the maximum production of carpospores apparently occurs just before this (Fig. 2).

Comparison of the curves in Figs. I and 3 shows that there is a close correlation between the number of plants bearing cystocarps on the shore and the vegetative growth cycle. This is to be expected, for the severe loss of frondage that occurs in late winter and early spring often leaves only the basal parts of the plants and these are not usually fertile. Thus the appearance of cystocarps must await the growth of the new season's branches.

\section{Spermatia}

Male plants are very much less common than tetrasporic or female plants, and have not been found in most of the collections made. For this reason the cycle of spermatium production is not as clear.

Male plants have been observed in January, February, March, May and November, while in June and September, when the largest numbers were seen, the active emission of spermatia has been witnessed. The observations suggest a summer maximum of spermatium production, occurring before the carpospore maximum (presumably coinciding with the most active production of mature carpogonia) and a winter minimum, probably in December (Fig. 2).

\section{Discussion}

As may be seen from the foregoing, the vegetative growth and fruiting cycles are closely related. The most active production of tetraspores and spermatia takes place during the period of fastest growth, when the bulk of plant material is reaching its maximum. The maximum of carpospore production appears to be later than the others, probably because the production of mature carpospores from a carpogonium, which involves fertilization and the production of a massive gonimoblast 'tissue', requires more time than the development of mature tetraspores or spermatangial sori from a modified cortical cell.

Thus numerous large plants producing immense numbers of tetraspores and carpospores are present on the shore in June, July and August. During this period the calmest weather may be expected in most years in the N. Atlantic (Bigelow \& Edmondson, 1947) and conditions for spore settlement should be most favourable.

This work formed part of an autecological study of $G$. verrucosa, carried out at the suggestion of Prof. L. Newton, whose advice and encouragement I am pleased to acknowledge. 


\section{SUMMARY}

The annual cycles of vegetative growth and reproduction of Gracilaria verrucosa are described. The former has been investigated by growing plants on a barge in the Menai Straits. Growth occurs throughout the year, being slow in winter and suddenly increasing in May-June to a higher level. It is suggested that the temperature of the sea water is the most important factor in controlling the growth rate.

The study of the reproductive cycles shows that spore production continues throughout the year, except for a short period in early spring (FebruaryMarch). The maximum production is in summer, tetraspores in July and carpospores in August-September. Spore production can be closely related to the vegetative growth cycle.

\section{REFERENCES}

AtkINs, W. R. G., I938. Photoelectric measurements of the seasonal variation in daylight. Proc. roy. Soc., Ser. A, Vol. 165, p. 453.

Bigelow, H. B. \& EDmondson, W. T., I947. Wind waves at sea, breakers and surf. Hydrographic Office U.S. Navy Publ., No. 602, pp. 72-80. Washington D.C.

Causey, N. B., Prytherch, J. P., McCaskill, J., Humm, H. J. \& Wolf, F. A., I946 Influence of environmental factors upon the growth of Gracilaria confervoides. Bull. Duke Univ. mar. Sta., Vol. 3, pp. 19-24.

Cotton, A. D., I9I2. Clare Island Survey. Marine Algae. Proc. R. Irish Acad., Vol. 31, Part I5, I78 pp.

Feldmann, J., I954. Inventaire de la Flora Marine de Roscoff. Trav. Sta.biol.Roscoff, Suppl. 6, I52 pp.

GIBB, D. C., I939. Some marine algal communities of Great Cumbrae. F. Ecol., Vol. 27, pp. 364-82.

Greville, R. K., I830. Algae Britannicae. Edinburgh.

HaRvey, H. W., I955. The Chemistry and Fertility of Sea Waters. Cambridge University Press. $224 \mathrm{pp}$.

Hudson, G., I762. Flora Anglica. London.

JONES, W. E., 1957. A note on the genus Cordylecladia J. Agardh. (Algae: Rhodophyceae) Ann. Mag. nat. Hist., Ser. 12, Vol. ro, pp. 70-I.

- 1959. Experiments on some effects of certain environmental factors on Gracilaria verrucosa (Hudson) Papenfuss. F. mar. biol. Ass. U.K., Vol. 38, pp 153-67.

May, V., 1948. The algal genus Gracilaria in Australia. Bull. Coun. sci. industr. Res. Aust., No. 235, 64 pp.

Rosenvinge, L. K., I93I. Marine Algae of Denmark. I. Rhodophyceae. K. danske vidensk. Selsk. Skr. Bd. 7, $627 \mathrm{pp}$.

Spencer, C. P., 1954. Studies on the culture of a marine diatom. F. mar. biol. Ass. U.K., Vol. 33, pp. 265-90. 